\title{
Activation of T-Cell-Factor-Dependent Transcription by Kaposi's Sarcoma-Associated Herpesvirus Replication Transactivation Activator
}

\author{
Seho Cha ${ }^{a}$ Hee Jung Yoon ${ }^{c}$ Su-Jung Kim ${ }^{b}$ Taegun Seo $^{a}$ \\ Departments of a Life Science and ${ }^{\mathrm{b}}$ Biological and Environmental Science, Dongguk University-Seoul, Seoul, and \\ 'Department of Internal Medicine, Eulji University School of Medicine, Daejeon, South Korea
}

\section{Key Words}

Kaposi's sarcoma-associated herpesvirus •

Replication transactivation activator $\cdot \mathrm{T}$ cell factor

\begin{abstract}
Objective: To elucidate the cellular function of Kaposi's sarcoma-associated herpesvirus (KSHV) replication transactivation activator (RTA) at the transcriptional level. Methods: Transcriptional activation of T-cell-factor (TCF)-dependent genes by RTA was determined using the luciferase reporter assay. The specific regions of RTA required for the activation of TCF-dependent transcription and association with $\beta$ catenin were established. Results: RTA specifically activated TCF-dependent transcription in a dose-dependent manner, to an extent comparable to the activation achieved by latency-associated nuclear antigen. In contrast, other KSHV viral proteins investigated, such as basic leucine zipper and viral interferon regulatory factor 1 , did not affect TCF-dependent transcription. The C-terminal region of RTA appeared to be necessary for transcription. However, RTA did not affect the $\beta$-catenin level or the subcellular localization thereof. Conclusion: Our results collectively demonstrate that KSHV RTA activates TCF-dependent transcription without involving the $\beta$-catenin pathway.

Copyright $\odot 2010$ S. Karger AG, Basel
\end{abstract}

\section{Introduction}

Wnt signaling is an evolutionarily conserved pathway that plays important roles in controlling a large and diverse set of cell fate decisions during embryonic development and tumorigenesis [1-3]. The intracellular signaling pathway of Wnt is also conserved throughout evolution. According to the currently accepted model, glycogen synthase kinase $3 \beta$ (GSK3B) phosphorylates cytoplasmic $\beta$-catenin prior to degradation in the absence of Wnt. Consequently, the cytoplasmic $\beta$-catenin levels remain low. Upon binding of Wnt to the Frizzled receptor family, signals are transmitted to the Dishevelled protein that antagonizes GSK3B activity. Wnt-induced inactivation of GSK3B leads to reduced phosphorylation of $\beta$ catenin, resulting in $\beta$-catenin accumulation in the cytoplasm. Accumulated $\beta$-catenin subsequently translocates to the nucleus, where it binds to the $\mathrm{T}$ cell factor (TCF) family that activates Wnt target gene expression [1, 3-5].

Kaposi's sarcoma-associated herpesvirus (KSHV), also known as human herpesvirus, is a $\gamma 2$-herpesvirus associated with Kaposi's sarcoma, primary effusion lymphoma and multicentric Castleman's disease [6-9]. Sequence analyses reveal that KSHV is closely related to herpesvirus saimiri and Epstein-Barr virus [10]. As with

Taegun Seo, $\mathrm{PhD}$

Department of Life Science

Dongguk University-Seoul, 26, 3 Pil-dong, Jung-gu

Seoul 100-715 (South Korea)

Tel. +82 22260 3318, Fax +82 22260 8769, E-Mail tseo@dongguk.edu 

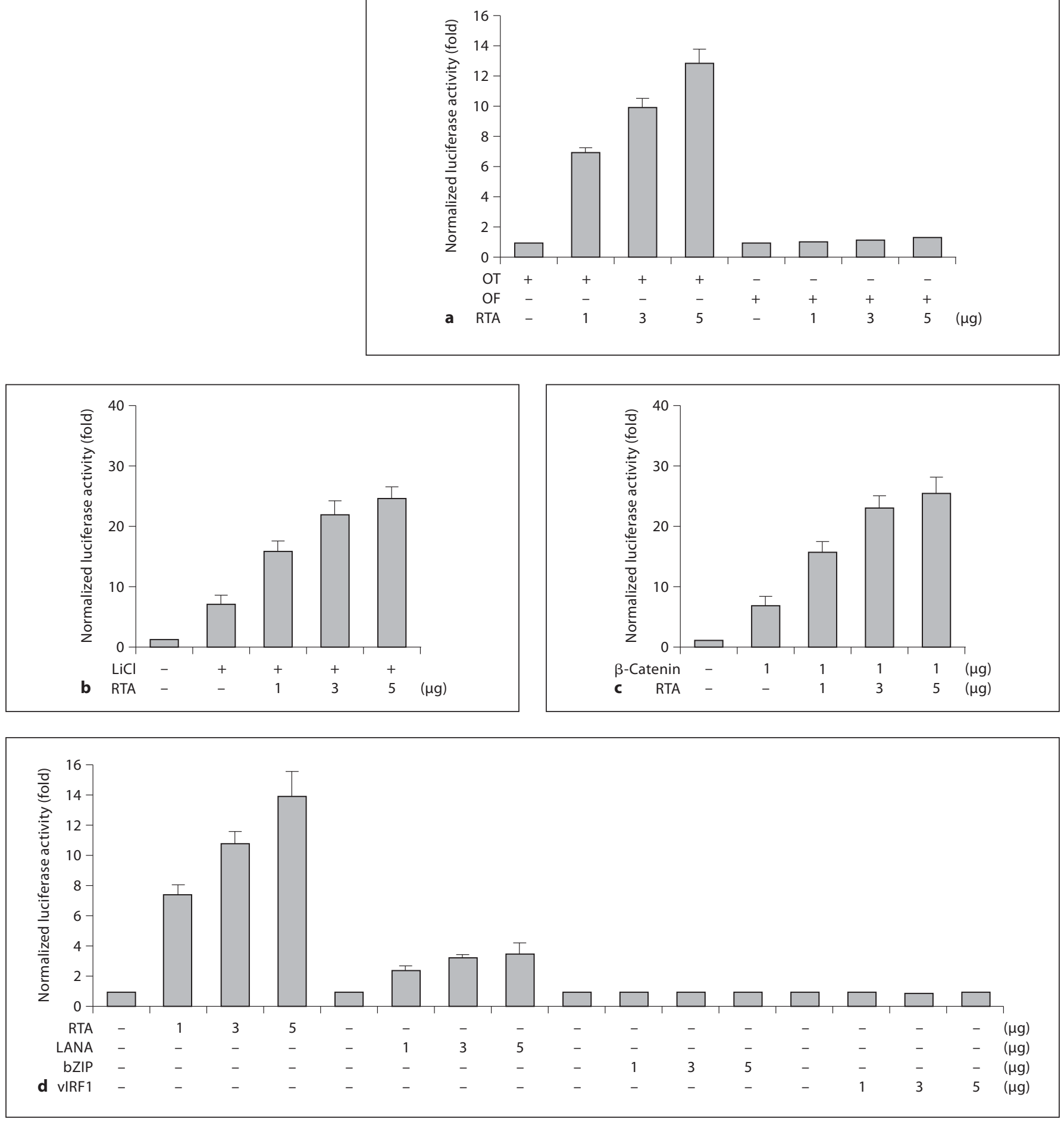

Fig. 1. RTA activates TCF-dependent transcription. a 293T cells in $60-\mathrm{mm}$ dishes were cotransfected with pGL3-OT $(1 \mu \mathrm{g})$ or pGL3-OF $(1 \mu \mathrm{g})$, pRSV/ $\beta$-gal $(0.5 \mu \mathrm{g})$ and increasing concentrations of expression plasmid encoding RTA. After $24 \mathrm{~h}$ of transfection, cells were harvested and luciferase activity measured. b 293T cells were cotransfected with pGL3-OT $(1 \mu \mathrm{g})$, pRSV/ $\beta$-gal $(0.5$ $\mu \mathrm{g})$ and increasing concentrations of expression plasmid encod- ing RTA. The cells were treated with $20 \mathrm{~mm} \mathrm{LiCl}$. c 293T cells were cotransfected with pGL3-OT $(1 \mu \mathrm{g}), \beta$-catenin expression plasmid $(1 \mu \mathrm{g})$, pRSV/ $\beta$-gal $(0.5 \mu \mathrm{g})$ and increasing concentrations of expression plasmid encoding RTA. d 293T cells were cotransfected with pGL3-OT $(1 \mu \mathrm{g})$ and pRSV/ $\beta$-gal $(0.5 \mu \mathrm{g})$, together with increasing concentrations of expression plasmids encoding RTA, LANA, bZIP and vIRF1, respectively. 
other herpesviruses, KSHV has two modes of infection, i.e. the latent and lytic states [11]. The latency of KSHV is disrupted by replication transactivation activator (RTA) expression [12].

KSHV RTA is a transcriptional activator that plays a pivotal role in the switch of the viral life cycle from latency to lytic replication [12-14]. RTA activates target promoters via direct DNA binding or via indirect interactions with cellular transcription factors such as RBP$\mathrm{J} / \mathrm{CBF} 1$, CCAAT-enhancer-binding protein- $\alpha$ and octamer transcription factor 1 [15-19]. The $\mathrm{N}$-terminal region of RTA contains a DNA-binding domain, whereas the C-terminal region has a strong transactivation domain $[12,20-22]$. A recent report shows that RTA functions as a ubiquitin E3 ligase and targets interferon regulatory factor 7 for proteasome-mediated degradation [23].

Here, we demonstrate that RTA stimulates TCF-dependent transcription, leading to activation of Wnt target genes. Interestingly, RTA specifically activates TCF-dependent transcription but does not alter the $\beta$-catenin level or the subcellular localization thereof. Our results suggest that RTA activates Wnt signaling without a requirement for GSK3B or $\beta$-catenin.

\section{Materials and Methods}

\section{Plasmids}

RTA, its deletion mutant expression plasmids and $\mathrm{pRSV} / \beta$-gal were kind gifts from Dr. Gwack [21, 24]. The TCF-luciferase reporter pGL3-OT, the mutant reporter pGL3-OF and the $\beta$-catenin expression plasmid were generously provided by Dr. Vogelstein (Johns Hopkins Medical Institution, Baltimore, Md., USA). Latency-associated nuclear antigen (LANA), basic leucine zipper (bZIP) and viral interferon regulatory factor 1 (vIRF1) expression plasmids were described in previous reports [25-27].

Cell Culture, Transfection and Reporter Assays

293T cells were maintained in Dulbecco's modified Eagle's medium supplemented with $10 \%$ fetal bovine serum. Transfection was performed by the calcium phosphate precipitation method [28].

\section{Reporter Assays}

At $24 \mathrm{~h}$ after transfection, cells were harvested and equal amounts of extracts employed for the detection of luciferase activity, measured using a luminometer. The total amount of transfected DNA was kept constant by the addition of blank vector. Activity of the reporter alone was set to a value of 1 , and luciferase measurements were normalized to those of the internal control, $\beta$-galactosidase.
Immunofluorescence

Cells were fixed in $3.7 \%$ formaldehyde for $30 \mathrm{~min}$ and permeabilized with phosphate-buffered saline (PBS) containing $0.2 \%$ Triton X-100 (PBST) on ice. After blockage with $1 \%$ bovine serum albumin (BSA), cells were incubated with primary antibody in PBST containing 1\% BSA for $1 \mathrm{~h}$ at room temperature, followed by 3 washes with PBST. Next, the cells were incubated with secondary antibody in PBST containing $1 \%$ BSA for $1 \mathrm{~h}$, and washed 3 times with PBST. Analyses were performed using a Zeiss (Oberkochen, Germany) confocal microscope with fluorescein isothiocyanate (FITC) and tetramethyl rhodamine isothiocyanate (TRITC) filter sets.

\section{Results}

\section{RTA Activates TCF-Dependent Transcription}

We investigated whether RTA modulated TCF-dependent transcription using cotransfection assays. 293T cells were transiently cotransfected with an RTA expression plasmid plus either a pGL3-OT reporter containing 3 copies of wild-type TCF binding sites or a pGL3-OF reporter with 3 copies of mutated binding sites. After $24 \mathrm{~h}$ of transfection, cells were harvested and assayed for luciferase activity as a measure of reporter gene expression. Expression of the pGL3-OT reporter was activated upon cotransfection of the RTA expression plasmid, in a dosedependent manner (fig. 1a). However, RTA did not activate expression of the pGL3-OF reporter containing mutant TCF binding sites (fig. 1a). $\mathrm{LiCl}$ is widely used to inhibit GSK3B and activates Wnt signaling [29]. After $12 \mathrm{~h}$ of transfection, cells were treated with $20 \mathrm{mM} \mathrm{LiCl}$ for $24 \mathrm{~h}$, harvested and assayed for luciferase activity. The $293 \mathrm{~T}$ cells exposed to LiCl exhibited a marked increase in pGL3-OT reporter gene expression, and cotransfected RTA synergistically activated such expression in a dosedependent manner (fig. 1b). Similarly, $\beta$-catenin activated reporter gene expression, and RTA synergistically and dose-dependently promoted TCF-dependent transcription (fig. 1c). Earlier studies showed that KSHV LANA activated TCF-dependent transcription by promoting translocation of GSK3B to the nucleus, leading to $\beta$ catenin accumulation [30-32]. As expected, LANA activated TCF-dependent transcription in a dose-dependent manner. Interestingly, RTA induced stronger reporter gene activity than did LANA (fig. 1d). We additionally examined the effects of KSHV bZIP and vIRF1 overexpression on TCF-dependent transcription. Neither KSHV bZIP nor vIRF1 affected TCF-dependent reporter activity (fig. 1d), implying that these viral proteins are not involved in Wnt signaling. 
Fig. 2. The C-terminal region of RTA is required for the activation of TCF-dependent transcription. WT $=$ Wild type. a Schematic representation of wild-type and mutant RTA. LZ = Leucine zipper; TAD $=$ transactivation domain. b $293 \mathrm{~T}$ cells were transfected with pME18s-RTA and mutants $(8 \mu \mathrm{g})$, respectively. After $48 \mathrm{~h}$ of transfection, cells were harvested and lysed. The cell lysates were immunoprecipitated (IP) with anti-Flag antibody and immunoblotted (IB) with anti-Flag antibody. Asterisk: nonspecific bands. c 293T cells were cotransfected with pGL3OT $(1 \mu \mathrm{g})$ and pRSV/ $\beta$-gal $(0.5 \mu \mathrm{g})$, together with wild-type, LXXAA, N599, N589 or N300 mutant RTA, respectively. After $24 \mathrm{~h}$ of transfection, the cells were harvested and luciferase (Luc) activities measured.

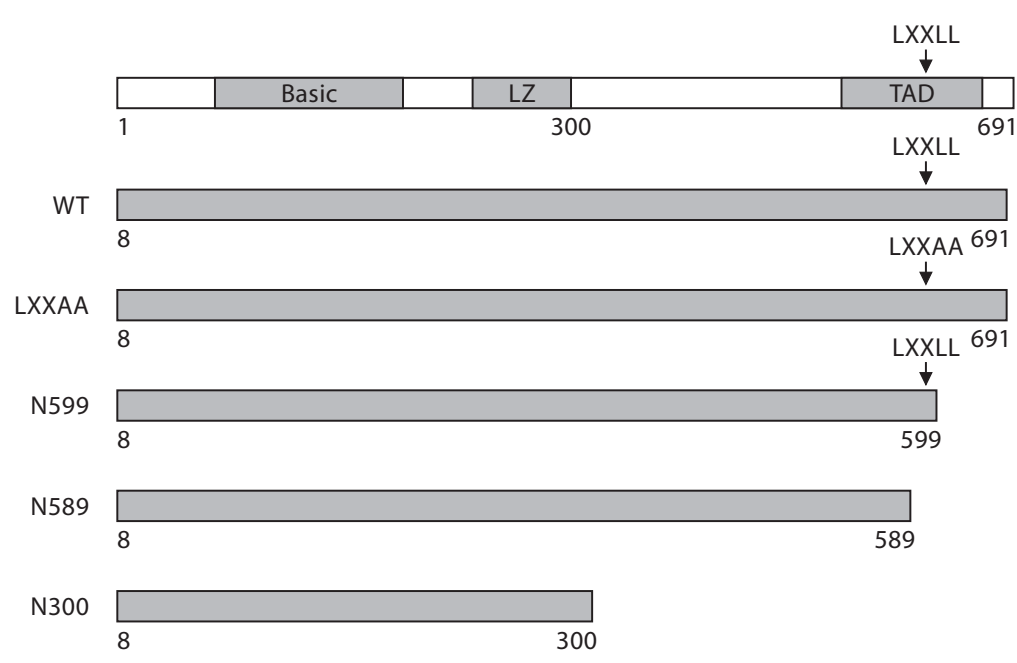

a
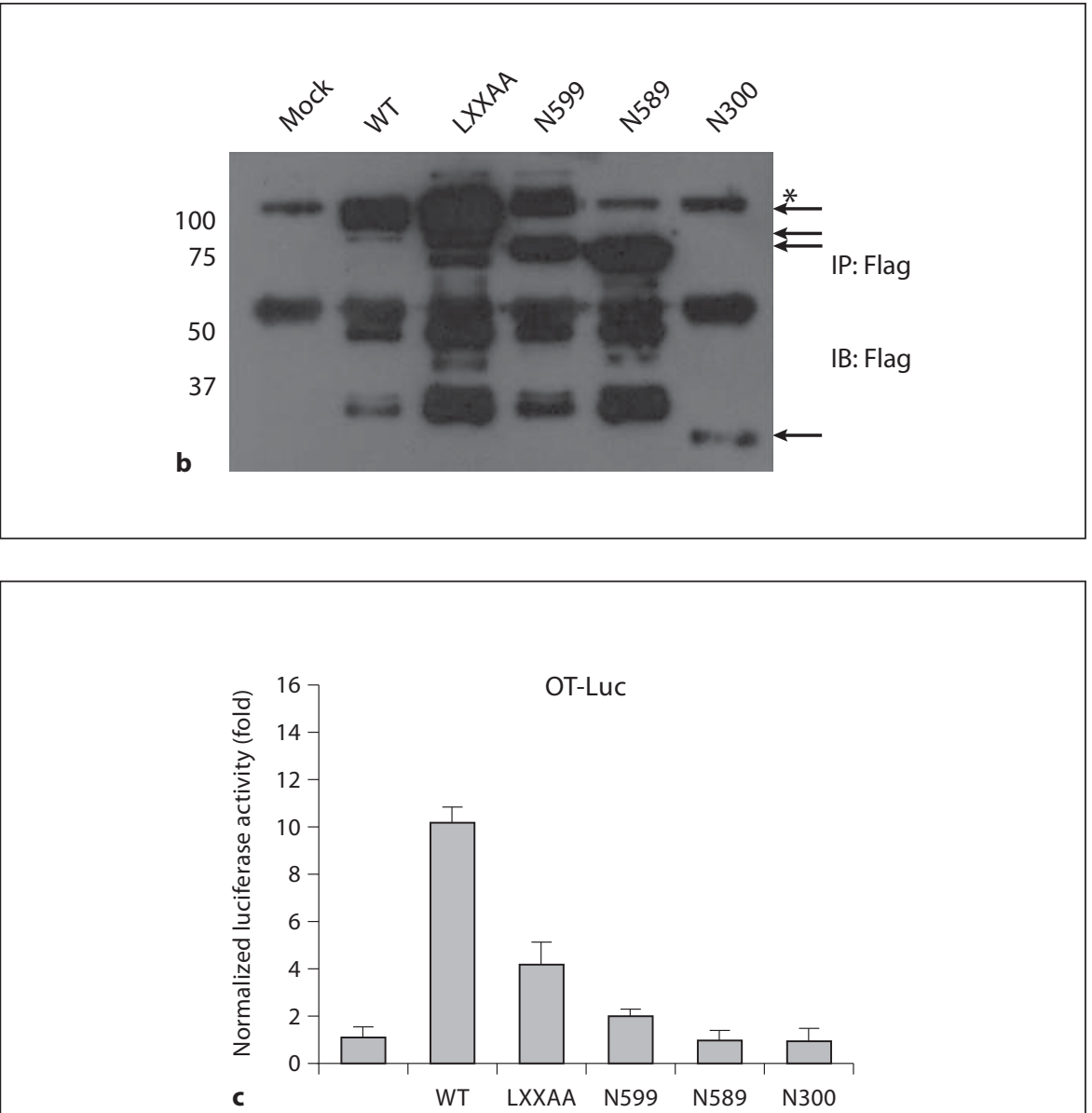
The C-Terminal Region of RTA Is Necessary for Activation of TCF-Dependent Transcription

To identify the precise region of RTA required for activation of TCF-dependent transcription, we constructed a series of RTA mutants, i.e. LXXAA, N599, N589 and N300 (fig. 2a). LXXAA was generated by substituting alanine (AA) for leucine (LL) in the LXXLL motif, which is the binding site of the coactivator CREB-binding protein. The LXXAA expression plasmid has been described in a previous report [24]. As shown in figure $2 b$, we confirmed that all of the RTA mutants were expressed in $293 \mathrm{~T}$ cells. Reporter assays were performed, in which $293 \mathrm{~T}$ cells were transiently cotransfected with combinations of the pGL3OT reporter and RTA deletion mutants. Decreased TCFdependent transcription was observed when C-terminaldeleted RTA mutants were employed, compared to wildtype RTA (fig. 2c). In the presence of LXXAA RTA, reporter gene induction was reduced by half, indicating that RTA-CBP interactions are involved in TCF-dependent transcription.

A total loss of reporter gene activation was observed with the N589 and N300 mutants (fig. 2c). Our data thus clearly demonstrate that the $\mathrm{C}$-terminal region of RTA is required for TCF-dependent transcription.

Activation of TCF-Dependent Transcription by RTA Is Not Related to $\beta$-Catenin Level or Localization

As TCF-dependent transcription occurs downstream of $\beta$-catenin, we assessed the $\beta$-catenin level and the subcellular localization thereof. 293T cells were cotransfected with wild-type or mutant RTA (LXXAA, N599, N589 or N300). After $24 \mathrm{~h}$ of transfection, the cells were harvested, and lysates immunoblotted with an anti- $\beta$ catenin antibody. The $\beta$-catenin level was not altered upon overexpression of either wild-type or mutant RTA (fig. 3a), suggesting that activation of TCF-dependent transcription was not associated with alterations in $\beta$ catenin level.

Next, we determined the effects of RTA on the subcellular localization of $\beta$-catenin. Following $24 \mathrm{~h}$ of transfection of 293T cells with green fluorescent protein (GFP) or GFP-RTA, we examined the subcellular localization of $\beta$-catenin using immunofluorescence confocal microscopy. Consistent with previous findings, GFP-RTA was located within the nucleus, whereas GFP alone displayed a diffuse pattern throughout both cytoplasm and nucleus. $\beta$-catenin was located mainly in the cytoplasmic region close to the membrane. In the presence of $\mathrm{LiCl}$, a GSK3B inhibitor, $\beta$-catenin was translocated to the nucleus, whereas RTA expression did not affect the subcel- lular localization of $\beta$-catenin (fig. $3 \mathrm{~b}$ ), indicating that TCF-dependent transcriptional activation by RTA was not related to $\beta$-catenin localization. Based on these results, we propose that RTA activates Wnt signaling without any requirement for the GSK3B and $\beta$-catenin pathways.

\section{Discussion}

KSHV has two general modes of infection. Specifically, these are latency and lytic replication. RTA is a switch protein that regulates the infection mode and induces the lytic phase by activating early and late genes in the KSHV lytic gene cluster. RTA activates a number of viral genes including PAN, open reading frame (ORF) 57/MTA, ORF56, ORF K2, ORF37, ORF K14, ORF K9/ vIRF1 and ORF52 [13, 14, 18, 20,33]. Whereas the transcriptional activation of KSHV viral gene expression by RTA has been extensively investigated, little is known about the transcriptional regulation of cellular gene expression by RTA. Here, we demonstrate that RTA specifically activates TCF-dependent transcription downstream of Wnt signaling. Interestingly, activation of TCF-dependent transcription by RTA is not associated with the canonical $\beta$-catenin/WNT pathway as RTA does not affect the cellular $\beta$-catenin level or its subcellular localization (fig. 3). In addition, no physical interactions between RTA and $\beta$-catenin were detectable (data not shown). LANA interacts with the C-terminus of GSK3B, inhibiting nuclear export and resulting in depletion of cytoplasmic GSK3B, which phosphorylates cytoplasmic $\beta$-catenin [30-32]. We observed no interactions between RTA and GSK3B (data not shown). Thus, the mechanism by which RTA activates TCF-dependent transcription may be different from that of LANA.

Another possible hypothesis is that RTA activates TCF-dependent transcription via direct binding with TCF or other associated factors. RTA acts as a strong transactivator when tethered to promoter regions [14, $16,18,20-22,33,34]$. The protein consists of an N-terminal DNA-binding domain, a central domain and a C-terminal acidic activation domain [22]. Thus, upon recruitment to the promoter regions of TCF-dependent genes through direct interactions, RTA may activate strong transcription. The finding that the $\mathrm{C}$-terminal region of RTA is necessary for TCF-dependent transcription (fig. 2) is consistent with this theory. However, further studies are required to clarify the pre- 


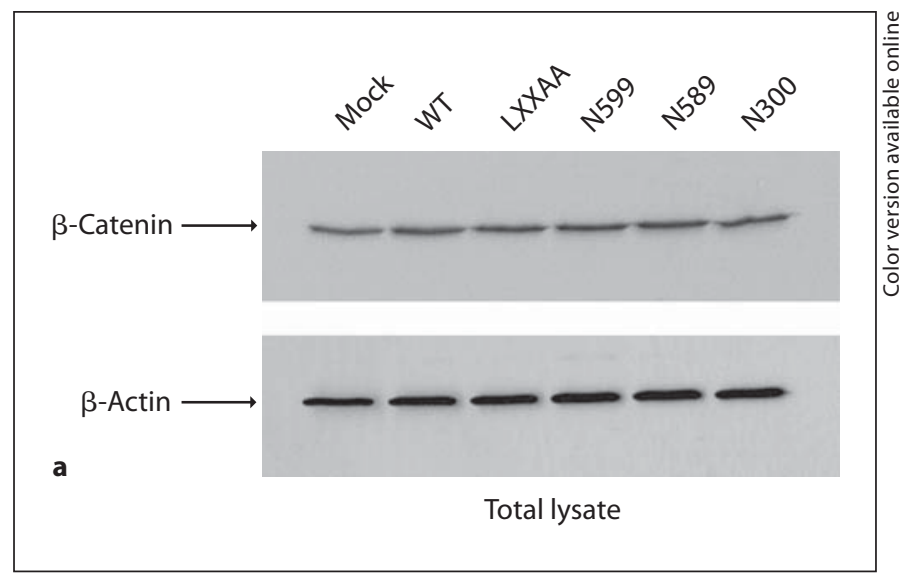

Fig. 3. RTA is not associated with the $\beta$ catenin pathway. a $293 \mathrm{~T}$ cells were transfected with wild-type, LXXAA, N599, N589 and N300 mutant RTA, respectively. After $24 \mathrm{~h}$ of transfection, the cells were harvested and lysed. Cell lysates were immunoblotted with anti- $\beta$-catenin monoclonal (upper panel) and anti- $\beta$-actin monoclonal antibodies (lower panel). $\mathrm{WT}=$ Wild type. b $293 \mathrm{~T}$ cells were cotransfected with GFP or GFP-RTA expression plasmids (upper panel) or were treated with $\mathrm{LiCl}$ ( $20 \mathrm{mM}$; lower panel). After $24 \mathrm{~h}$, the cells were fixed, incubated with anti- $\beta$-catenin monoclonal antibody and detected with TRITC-conjugated antimouse antibody. The cells were examined under a confocal microscope using the FITC and TRITC filter sets. DIC = Differential interference contrast microscopy.

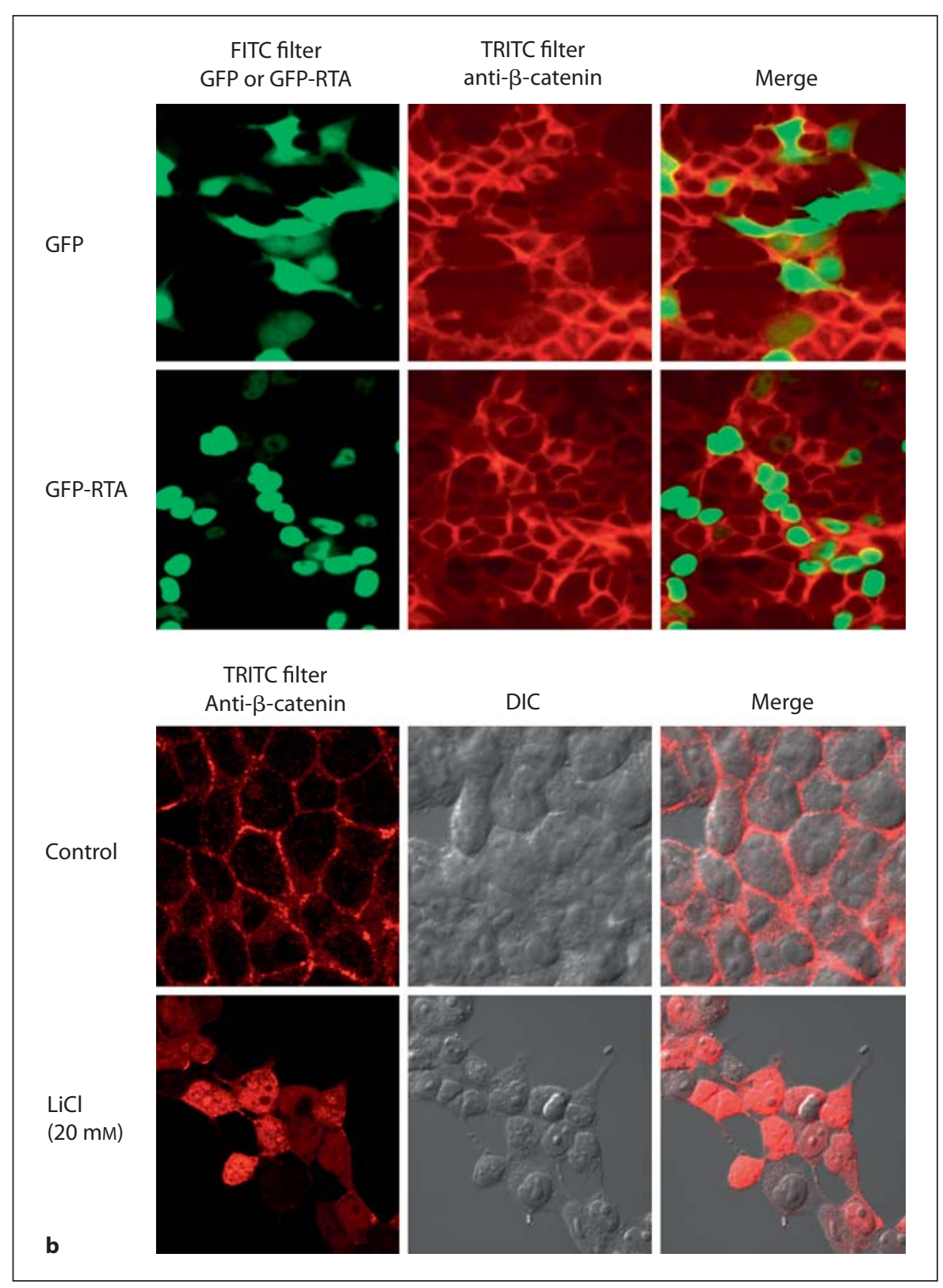


cise mechanism of RTA-mediated TCF-dependent transcription.

TCF-dependent transcription is the final downstream event of canonical Wnt signaling. Therefore, it appears that RTA mimics Wnt activation. As the Wnt signaling pathway is implicated in human cancer, RTA may be associated with the development of KSHV-related neoplasia.

\section{Acknowledgment}

This work was supported by the Korea Research Foundation Grant funded by the Korean Government (MOEHRD) (KRF2006-521-C00133).

\section{References}

1 Taketo MM: Wnt signaling and gastrointestinal tumorigenesis in mouse models. Oncogene 2006;25:7522-7530.

$\checkmark 2$ Barolo S: Transgenic Wnt/TCF pathway reporters: all you need is LEF? Oncogene 2006; 25:7505-7511.

-3 Wodarz A, Nusse R: Mechanisms of Wnt signaling in development. Annu Rev Cell Dev Biol 1998;14:59-88

4 Kikuchi A: Regulation of beta-catenin signaling in the Wnt pathway. Biochem Biophys Res Commun 2000;268:243-248.

5 Logan CY, Nusse R: The Wnt signaling pathway in development and disease. Annu Rev Cell Dev Biol 2004;20:781-810.

-6 Chang Y, Cesarman E, Pessin MS, Lee F, Culpepper J, Knowles DM, Moore PS: Identification of herpesvirus-like DNA sequences in AIDS-associated Kaposi's sarcoma. Science 1994;266:1865-1869.

7 Cesarman E, Chang Y, Moore PS, Said JW, Knowles DM: Kaposi's sarcoma-associated herpesvirus-like DNA sequences in AIDSrelated body-cavity-based lymphomas. $\mathrm{N}$ Engl J Med 1995;332:1186-1191.

8 Moore PS, Chang Y: Detection of herpesvirus-like DNA sequences in Kaposi's sarcoma in patients with and without HIV infection. N Engl J Med 1995;332:1181-1185.

-9 Soulier J, Grollet L, Oksenhendler E, Cacoub P, Cazals-Hatem D, Babinet P, d'Agay MF, Clauvel JP, Raphael M, Degos L, et al: Kaposi's sarcoma-associated herpesvirus-like DNA sequences in multicentric Castleman's disease. Blood 1995;86:1276-1280

10 Russo JJ, Bohenzky RA, Chien MC, Chen J, Yan M, Maddalena D, Parry JP, Peruzzi D, Edelman IS, Chang Y, Moore PS: Nucleotide sequence of the Kaposi sarcoma-associated herpesvirus (HHV8). Proc Natl Acad Sci USA 1996;93:14862-14867.

11 Jenner RG, Alba MM, Boshoff C, Kellam $\mathrm{P}$ : Kaposi's sarcoma-associated herpesvirus latent and lytic gene expression as revealed by DNA arrays. J Virol 2001;75:891902
12 Lukac DM, Renne R, Kirshner JR, Ganem D: Reactivation of Kaposi's sarcoma-associated herpesvirus infection from latency by $\mathrm{ex}$ pression of the ORF 50 transactivator, a homolog of the EBV R protein. Virology 1998 252:304-312.

13 Sun R, Lin SF, Gradoville L, Yuan Y, Zhu F, Miller G: A viral gene that activates lytic cycle expression of Kaposi's sarcoma-associated herpesvirus. Proc Natl Acad Sci USA 1998;95:10866-10871.

14 Gradoville L, Gerlach J, Grogan E, Shedd D, Nikiforow S, Metroka C, Miller G: Kaposi's sarcoma-associated herpesvirus open reading frame 50/RTA protein activates the entire viral lytic cycle in the HH-B2 primary effusion lymphoma cell line. J Virol 2000;74 6207-6212.

15 Wang SE, Wu FY, Yu Y, Hayward GS: CCAAT/enhancer-binding protein-alpha is induced during the early stages of Kaposi's sarcoma-associated herpesvirus (KSHV) lytic cycle reactivation and together with the KSHV replication and transcription activator (RTA) cooperatively stimulates the viral RTA, MTA, and PAN promoters. J Virol 2003;77:9590-9612.

16 Liang Y, Chang J, Lynch SJ, Lukac DM, Ganem D: The lytic switch protein of KSHV activates gene expression via functional interaction with RBP-JK (CSL), the target of the Notch signaling pathway. Genes Dev 2002; 16:1977-1989.

17 Sakakibara S, Ueda K, Chen J, Okuno T, Yamanishi K: Octamer-binding sequence is a key element for the autoregulation of Kaposi's sarcoma-associated herpesvirus ORF50/ Lyta gene expression. J Virol 2001;75:68946900.

18 Song MJ, Li X, Brown HJ, Sun R: Characterization of interactions between RTA and the promoter of polyadenylated nuclear RNA in Kaposi's sarcoma-associated herpesvirus/ human herpesvirus 8. J Virol 2002;76:50005013
19 Lukac DM, Garibyan L, Kirshner JR, Palmeri D, Ganem D: DNA binding by Kaposi's sarcoma-associated herpesvirus lytic switch protein is necessary for transcriptional activation of two viral delayed early promoters. J Virol 2001;75:6786-6799.

20 Chang PJ, Shedd D, Gradoville L, Cho MS, Chen LW, Chang J, Miller G: Open reading frame 50 protein of Kaposi's sarcoma-associated herpesvirus directly activates the viral PAN and $\mathrm{K} 12$ genes by binding to related response elements. J Virol 2002;76:31683178 .

21 Gwack Y, Byun H, Hwang S, Lim C, Choe J: CREB-binding protein and histone deacetylase regulate the transcriptional activity of Kaposi's sarcoma-associated herpesvirus open reading frame 50. J Virol 2001;75:19091917.

22 Lukac DM, Kirshner JR, Ganem D: Transcriptional activation by the product of open reading frame 50 of Kaposi's sarcoma-associated herpesvirus is required for lytic viral reactivation in B cells. J Virol 1999;73:93489361.

23 Yu Y, Wang SE, Hayward GS: The KSHV immediate-early transcription factor RTA encodes ubiquitin E3 ligase activity that targets IRF7 for proteosome-mediated degradation. Immunity 2005;22:59-70.

24 Gwack Y, Hwang S, Byun H, Lim C, Kim JW, Choi EJ, Choe J: Kaposi's sarcoma-associated herpesvirus open reading frame 50 represses p53-induced transcriptional activity and apoptosis. J Virol 2001;75:6245-6248.

25 Lim C, Sohn H, Gwack Y, Choe J: Latencyassociated nuclear antigen of Kaposi's sarcoma-associated herpesvirus (human herpesvirus-8) binds ATF4/CREB2 and inhibits its transcriptional activation activity. J Gen Virol 2000;81:2645-2652

26 Park J, Seo T, Hwang S, Lee D, Gwack Y, Choe J: The K-bZIP protein from Kaposi's sarcoma-associated herpesvirus interacts with p53 and represses its transcriptional activity. J Virol 2000;74:11977-11982. 
-27 Seo T, Park J, Lee D, Hwang SG, Choe J: Viral interferon regulatory factor 1 of Kaposi's sarcoma-associated herpesvirus binds to p53 and represses p53-dependent transcription and apoptosis. J Virol 2001;75:6193-6198.

28 Graham FL, van der Eb AJ: A new technique for the assay of infectivity of human adenovirus 5 DNA. Virology 1973;52:456-467.

-29 Hedgepeth CM, Conrad LJ, Zhang J, Huang HC, Lee VM, Klein PS: Activation of the Wnt signaling pathway: a molecular mechanism for lithium action. Dev Biol 1997;185:82-91.
30 Fujimuro M, Wu FY, ApRhys C, Kajumbula H, Young DB, Hayward GS, Hayward SD: A novel viral mechanism for dysregulation of beta-catenin in Kaposi's sarcoma-associated herpesvirus latency. Nat Med 2003;9:300306.

31 Fujimuro M, Hayward SD: The latency-associated nuclear antigen of Kaposi's sarcomaassociated herpesvirus manipulates the activity of glycogen synthase kinase- $3 \beta$. J Virol 2003;77:8019-8030.

32 Liu J, Martin H, Shamay M, Woodard C, Tang QQ, Hayward SD: Kaposi's sarcomaassociated herpesvirus LANA protein downregulates nuclear glycogen synthase kinase 3 activity and consequently blocks differentiation. J Virol 2007;81:4722-4731.
$33 \mathrm{Bu}$ W, Palmeri D, Krishnan R, Marin R, Aris VM, Soteropoulos P, Lukac DM: Identification of direct transcriptional targets of the Kaposi's sarcoma-associated herpesvirus RTA lytic switch protein by conditional nuclear localization. J Virol 2008;82:1070910723.

34 Song MJ, Hwang S, Wong W, Round J, Martinez-Guzman D, Turpaz Y, Liang J, Wong B, Johnson RC, Carey M, Sun R: The DNA architectural protein HMGB1 facilitates RTAmediated viral gene expression in gamma-2 herpesviruses. J Virol 2004;78:12940-12950. 